\title{
Cigarette Smoke Induces Rapid Changes in Gene Expression in Pulmonary Arteries
}

\author{
Joanne L. Wright, Hsin Tai, Jin Dai, and Andrew Churg \\ Department of Pathology, University of British Columbia, Vancouver, British Columbia, Canada
}

\begin{abstract}
SUMMARY: The pathogenesis of cigarette smoke-induced pulmonary hypertension is not well characterized. We used RT-PCR to examine gene expression of nitric oxide synthase 2 (NOS-2), nitric oxide synthase 3 (NOS-3), endothelin, and vascular endothelial growth factor (VEGF) and its flk-1 receptor (VEGF-R) in main pulmonary arteries and in intraparenchymal arteries microdissected from alcohol-fixed paraffin blocks. The main pulmonary artery and intraparenchymal vessels responded in a similar fashion, with up-regulation of endothelin, VEGF, and VEGF-R gene expression evident by 2 hours after smoke exposure. Up-regulation of gene expression was still present at 24 hours after exposure, and at this time there was also a small increase in NOS-2. As a comparison, we examined the trachea and microdissected intraparenchymal airways and found up-regulation of endothelin and NOS-2 at 2 hours and additional up-regulation of NOS-3 at 24 hours. These findings suggest that the pulmonary vasculature very rapidly responds to cigarette smoke with up-regulation of mediators that control vascular cell proliferation and vascular constriction. These changes support the idea that pulmonary hypertension in cigarette smokers reflects a direct effect of smoke on the vasculature. The pattern of response in the vessels is distinctly different from that in the airways. (Lab Invest 2002, 82:1391-1398).
\end{abstract}

$P^{4}$ ulmonary hypertension will develop in approximately $6 \%$ of cigarette smokers with chronic obstructive lung disease (Burrows et al, 1972), but the pathogenesis of pulmonary hypertension in smokers is unclear. The traditional view is that hypertension is secondary to loss of vascular bed from emphysema (Murphy and Bone, 1984). However, there is some evidence to suggest that there is a direct effect of cigarette smoke on the pulmonary arteries, with production of the contractile ecosanoid endothelin, and stimulation of cell proliferation (see "Discussion").

One way to assess the effects of cigarette smoke on the pulmonary vasculature is to look for evidence of changes in gene expression. In a previous study using bulk lung samples, we showed that smoke transiently increased inducible nitric oxide synthase (iNOS or NOS-2) expression and increased endothelial NOS (eNOS or NOS-3) expression over the long term (Wright et al, 1999a). Because nitric oxide is an important vasodilator, these data also suggest that smoke might affect production of mediators that modify vasoconstriction.

Betsuyaku and colleagues (2001) have recently demonstrated the value of laser capture microdissection for evaluation of gene expression in the airways in bleomycin-induced lung injury. Of particular impor-

DOI: 10.1097/01.LAB.0000032806.45023.08

Received May 26, 2002.

This work was supported by a grant from the Heart and Stroke Foundation of British Columbia and Yukon, and Grants 53157 and 42539 from the Canadian Institutes for Health Research.

Address reprint requests to: Dr. J. L. Wright, Department of Pathology, 2211 Wesbrook Mall, Vancouver, British Columbia, Canada, V6T 2 B5.

E-mail: jlwright@interchange.ubc.ca tance is the fact that they noted a significant difference between the data accrued from bulk lung samples and from the laser capture microdissection samples. The present study was designed to determine whether microdissection would allow characterization of gene expression in the pulmonary vessels and whether this was different from gene expression in the airways after smoke exposure. As a further comparison, we also examined gene expression in the main pulmonary artery and the trachea to determine whether these structures showed the same changes seen in the intrapulmonary arteries and airways.

\section{Results}

Sprague-Dawley rats were exposed to the whole smoke of seven cigarettes. Two hours or 24 hours after the beginning of smoke exposure, the animals were killed and the lungs removed and inflated with cold $100 \%$ ethanol. The tracheal and main pulmonary artery were also fixed in cold ethanol. After fixation, sections of lung were embedded in paraffin, and multiple 20- $\mu$ m-thick sections were cut. One section was deparaffinized and stained with hematoxylin and eosin (HE) to serve as a dissection guide. The remaining sections were left unstained, and the paraffin was not removed. Hand microdissection of intrapulmonary arteries and airways was performed on these sections using an inverted phase contrast microscope and a fine needle. RT-PCR was carried out using traditional methods as described in "Materials and Methods," and the products were visualized with ethidium bromide stained gels; it was necessary to microdissect 30 to 50 sections to obtain a signal by RT-PCR. Similar methods were applied to the alcohol-fixed trachea and main pulmonary artery. 
Hand microdissection proved to be an accurate method of isolating small pulmonary arteries and airways (Fig. 1). The range of vessel diameters for vessels isolated from the control animals was 0.30 to $1.82 \mathrm{~mm}$, compared with 0.48 to $1.33 \mathrm{~mm}$ in the smoke-exposed animals. Similarly the range of airway diameters was 0.57 to $1.58 \mathrm{~mm}$ from the control animals, compared with 0.31 to 1.59 in the smokeexposed animals.

Figures 2 and 3 show changes in gene expression. For ease of visual comparison, control levels have all been normalized to 100 . Two hours after smoke exposure, the mainstem pulmonary artery and the intraparenchymal arteries showed an approximate doubling of gene expression of vascular endothelial growth factor (VEGF) (pulmonary artery: $p<0.001$; intraparenchymal arteries: $p=0.002$ ) and its flk-1 receptor (VEGF-R) (each $p<0.001)$ and endothelin (pulmonary artery: $p<0.001$; intraparenchymal arteries $<0.01$ ), with no changes in NOS-2 or NOS-3 compared with the control animals. By contrast, the trachea and intraparenchymal airways showed 2- to 2.5-fold increases in mRNA for endothelin (each $p<$ 0.001 ) and NOS-2 (each $p<0.001$ ) but no changes in VEGF, VEGF-R, or NOS-3.

Twenty-four hours after smoke exposure, VEGF, VEGF-R, and endothelin mRNA levels continued to be increased in the mainstem pulmonary artery of the smoke-exposed animals compared with controls (respective $p$ values $<0.01,0.01$, and 0.001 ), whereas in the intraparenchymal vessels, VEGF and VEGR-R remained increased (respective $p$ values $<0.02,0.01$ ), but the relative increases were less than at 2 hours. $A$ small increase in the levels of NOS-2 was identified in the intrapulmonary arteries $(p=0.05)$ of the smokeexposed animals. At this time endothelin mRNA levels also continued to be increased in the trachea $(p=$ 0.01 ) and intraparenchymal airways ( $p<0.05$ ); similarly NOS-2 levels were elevated in the airways $(p=$ 0.03) of the smoke-exposed animals (the increased levels in the trachea samples did not attain statistical significance, $p=0.06$ ). Again, the relative increases were smaller than at 2 hours. In addition, the smokeexposed animals had increases in NOS-3 levels of $40 \%$ to $50 \%$ in both trachea $(p<0.05)$ and in the airways $(p<0.01)$.

\section{Discussion}

In this study we have used hand microdissection and traditional methods of RT-PCR to examine gene expression in specific intrapulmonary structures. This approach offers the advantage that it potentially allows examination of airways and vessels of specific sizes, something that is difficult with the frozen sections usually used in laser capture microdissection. As well, the ability to fix tissues and embed them allows convenient preservation and preparation for RT-PCR. We had hoped, initially, that the technique could be adopted to formalin-fixed lung, but we were unable to obtain satisfactory RNA yields with formalin and, after trial and error, adopted $100 \%$ ethanol as the best fixative. The major disadvantage of this approach is that dissection of large numbers of sections is required to obtain a signal, a procedure that is time consuming and laborious. In addition, it is unclear whether we could ever dissect enough sections to obtain signals from much smaller structures, for example, airway epithelium. However, we are currently adapting this technique for use with real-time PCR, and we may be able to substantially decrease the number of microdissected sections required, so that

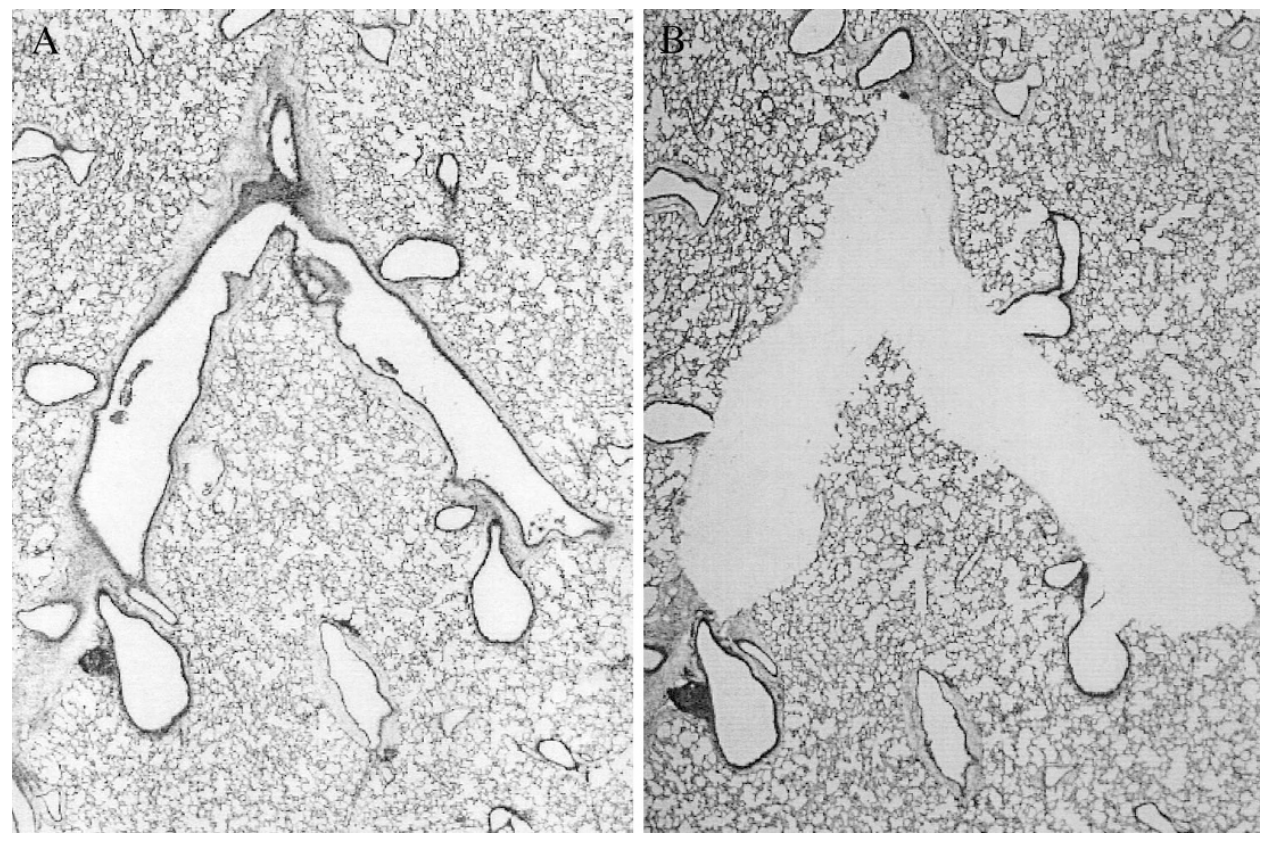

Figure 1.

Illustration of the results of hand microdissection of an intraparenchymal airway. Note that the entirety of the airway including epithelium and wall is removed. 
A

Gene Expression in Trachea

C

Control Smoke
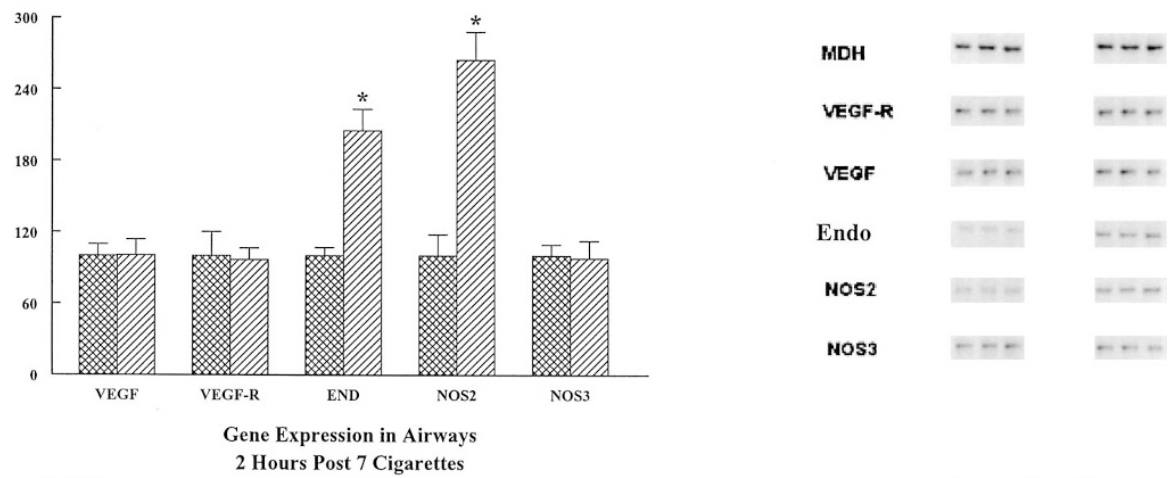

$\mathrm{C}$

प्यात $\mathrm{s}$

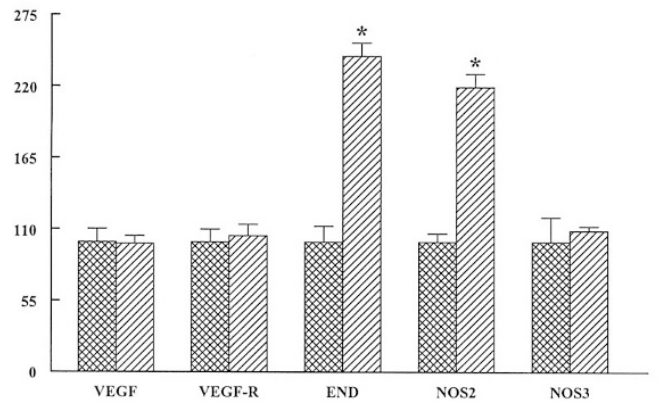

Control Smoke

B
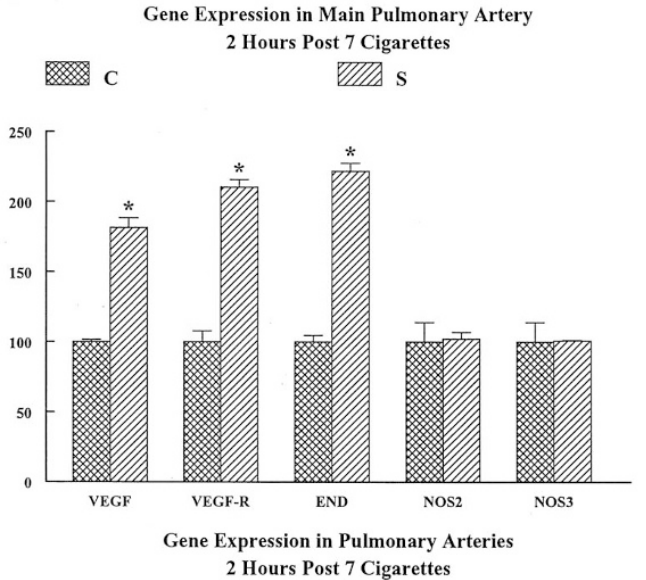

Control Smoke

c

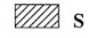
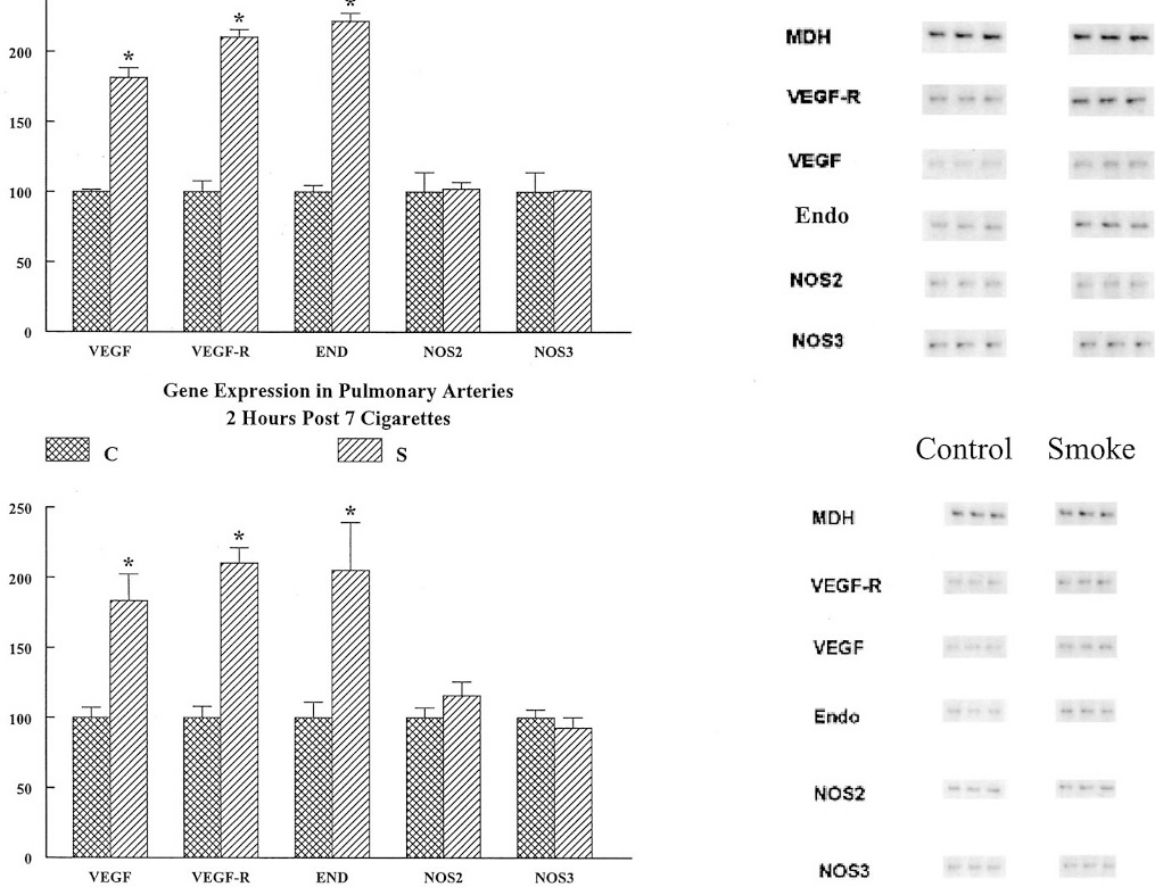

Control Smoke

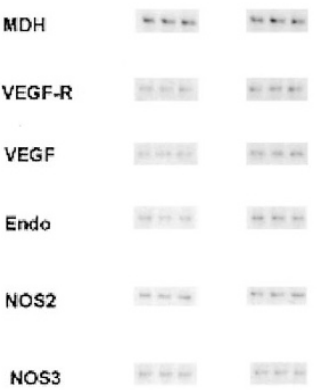

Figure 2.

A, mRNA levels from the trachea and intraparenchymal airways; $B$, levels from the main pulmonary artery and the intraparenchymal pulmonary arteries, 2 hours after exposure to the smoke of seven cigarettes. The control values are normalized to 100, to allow for easy comparison with mRNA levels for the smoke-exposed animals. Values are mean $\pm \mathrm{SD}$. *Significant difference compared with control levels. The corresponding ethidium bromide gels are adjacent to the graphs. 

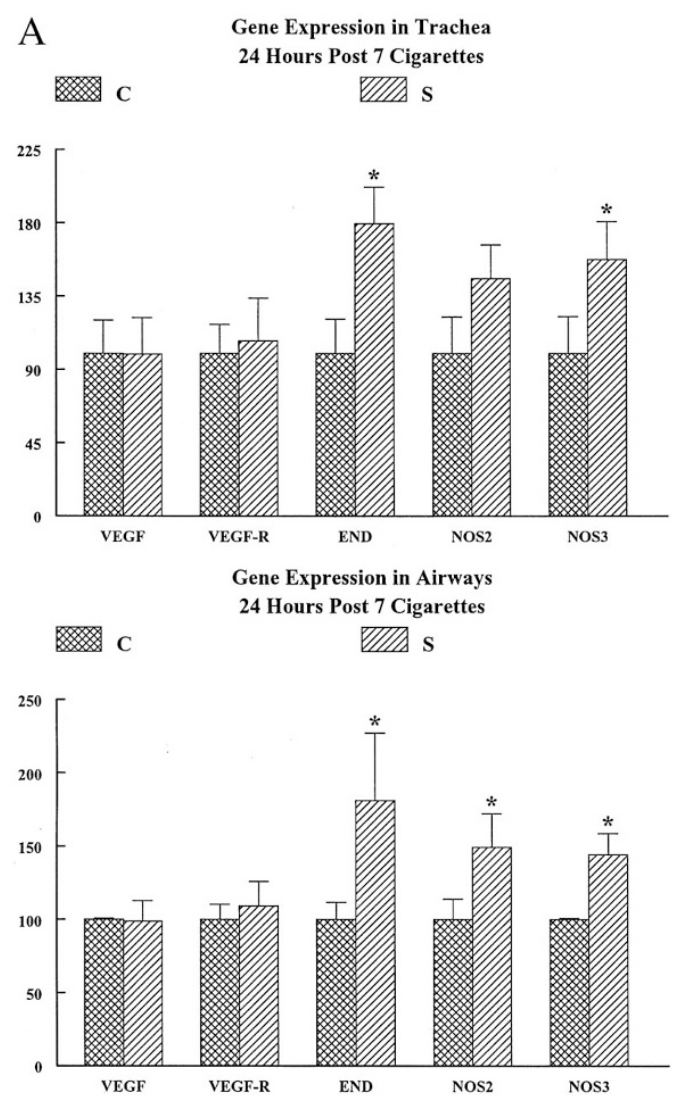

B
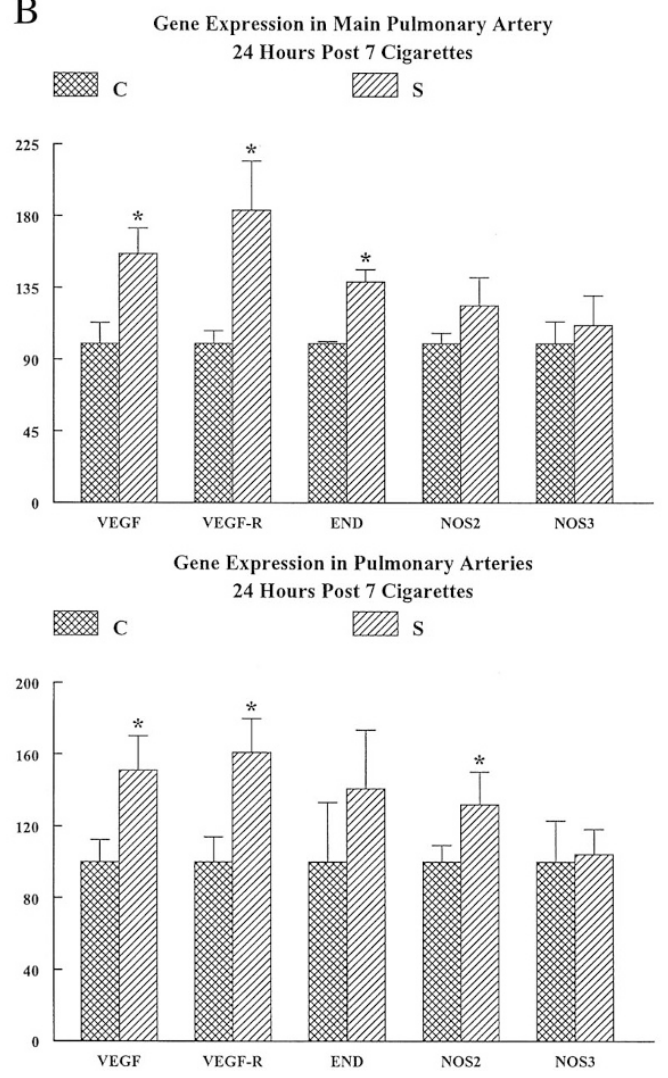

Control Smoke

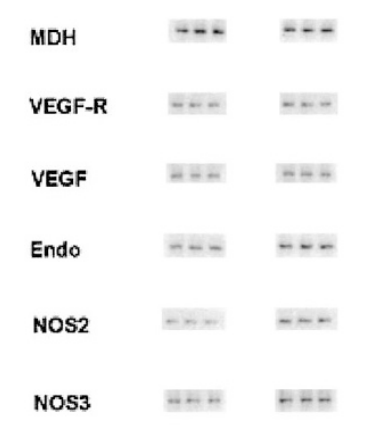

Control Smoke

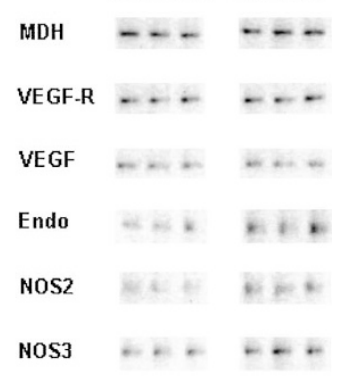

Control Smoke

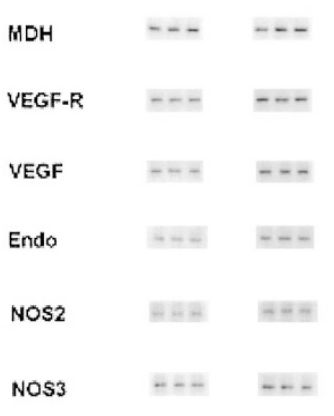

Control Smoke

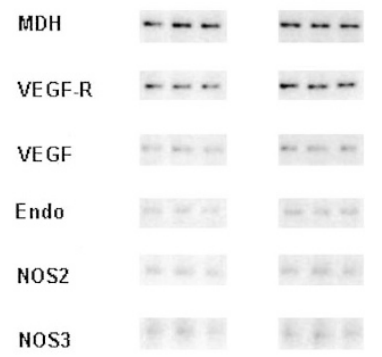

Figure 3.

A, mRNA levels from the trachea and intraparenchymal airways; B, levels from the main pulmonary artery and the intraparenchymal pulmonary arteries, 24 hours after exposure to the smoke of seven cigarettes. The control values are normalized to 100, to allow for easy comparison with mRNA levels for the smoke-exposed animals. Values are mean \pm SD. ${ }^{\star}$ Significant difference compared with control levels. The corresponding ethidium bromide gels are adjacent to the graphs. 
smaller structures or very narrow size ranges of vessels and airways could be examined.

Our results show for the first time that cigarette smoke rapidly (within 2 hours) up-regulates expression of a variety of genes coding for mediators important in vasoconstriction, vasodilatation, and vascular cell proliferation in the pulmonary vasculature; that these changes persist over 24 hours after a single smoke exposure; and that similar changes are seen in the intrapulmonary branches of the pulmonary artery and in the main pulmonary artery, perhaps implying both direct effects on the arteries and induction of circulating mediators as well. Smoke also rapidly up-regulates gene expression in the intrapulmonary airways and trachea, but the pattern of gene upregulation is, for the most part, different from that in the vessels.

One of the mediators found to be up-regulated in this study is endothelin, a potent constrictor of both vessels and airways and an inducer of smooth muscle cell proliferation. We have previously shown that acute exposure to cigarette smoke invokes a proliferative response in both the airways and the lung vasculature (Sekhon et al, 1994) and that this acute response seems to involve or to be invoked by endothelin, because it can be partially, but not completely, blocked by endothelin receptor antagonists (Dadmanesh and Wright, 1997).

Other workers have found that endothelin receptor inhibition reduces the vascular remodeling associated with pulmonary hypertension induced by hypoxia, embolism, or monocrotaline (Kim et al, 1999; reviewed in Roux et al, 1999). Endothelin is known to stimulate DNA synthesis in pulmonary artery smooth muscle cells, through a mechanism mediated by the $\mathrm{ET}_{\mathrm{A}}$ and $\mathrm{ET}_{\mathrm{B}}$ receptors, and it has been recently demonstrated that there is an increased concentration of endothelin receptors in the lung parenchyma of patients with pulmonary hypertension (Davie et al, 2002). Whether increased levels of endothelin are important in the genesis of pulmonary hypertension in smokers remains unclear, but in addition to the acute response, we have found that when guinea pigs are chronically exposed to cigarette smoke for periods of greater than 4 months, vascular cell proliferation continues (Wright and Sun, 1999), suggesting that endothelin might well be playing a continuing role. In addition, there is an increased amount of circulating endothelin in cigarette smokers (Goerre et al, 1995; Yildiz et al, 1996) and in patients with chronic obstructive pulmonary disease (Roland et al, 2001; Trakada et al, 2001). Our current results support these studies and suggest that increased endothelin production is probably a direct effect of smoke on both airways and vessels.

In a previous study, using bulk lung analysis, we observed up-regulation of both NOS-2 and NOS-3 in a distinct time sequence after cigarette smoke exposure. The present data extend these results and indicate that the acute increases previously reported in NOS gene expression probably originated in the airways rather than the vessels. Both the trachea and intraparenchymal airways exhibited an acute up- regulation of NOS-2, followed by up-regulation of NOS-3 at 24 hours in the smoke-exposed animals, whereas changes in NOS gene expression in the arteries were at most minimal.

The importance of the balance between endothelin and nitric oxide in the regulation and physiologic reaction of smooth muscle cells has become increasingly apparent (Hunley et al, 1995; Levin, 1995; Wort et al, 2001). Endothelin stimulates production and release of nitric oxide (Zellers et al, 1994), and activation of nitric oxide production dissociates endothelin from its receptors, in addition to interfering with the pathway for calcium mobilization (Redmond et al, 1996), thus inhibiting end-responses to endothelin (Goligorsky et al, 1994). Importantly, there seems to be a strong relationship between NOS up-regulation and the onset of vascular remodeling in experimental animal models of hypoxic hypertension (Xue and Johns, 1996). Furthermore, Kim et al (2000) have recently shown that the vascular remodeling distal to a ligature is associated with an increase in endothelin receptor expression in addition to increased NOS-3 expression. Finally, long-term smoking seems to be associated with a decreased nitric oxide response (Kiowski et al, 1994), with impaired endothelium-dependent relaxation of the pulmonary artery found in patients with chronic obstructive pulmonary disease (DinhXuan et al, 1991, 1993).

The present data also demonstrate up-regulation of VEGF and its flk-1 receptor. Because of its role in vascular remodeling, VEGF potentially is an important factor in pulmonary hypertension (Voelkel and Tuder, 1995). Indeed, an increased expression of VEGF has been identified in the medial smooth muscle of arteries in the lungs of patients with pulmonary hypertension secondary to a variety of etiologies (Hirose et al, 2000), and a recent study has demonstrated an increased serum level in patients with nighttime hypoxia caused by sleep apnea (Schulz et al, 2002). Many investigators have shown that VEGF is actually increased by hypoxia in cell cultures or in animals in which pulmonary hypertension was induced through hypoxia (Christou et al, 1998). This increase seems to take place primarily through transcriptional up-regulation (Klekamp et al, 1997; Tuder et al, 1995). Interestingly, VEGF seems to augment nitric oxide release from the endothelium (Scalia et al, 1999), and VEGF and the VEGF-R produce an angiogenic response via a nitric oxide-mediated mechanism (Bussolati et al, 2001).

It is important to emphasize that this study is restricted to the examination of gene transcription and is very acute. We do not as yet know whether, and to what extent, these changes lead to increases in protein production nor how these acute changes will relate to chronic ones. As well, cigarette smoke exposure does not seem to be associated with acute changes in vascular reactivity. For example, we have previously demonstrated that acute cigarette smoke exposure will produce immediate airway constriction in lung slice explants (Wright et al, 1999b) and in vivo will produce physiologic changes of increased airways resistance with air trapping and airflow abnormalities, 
but it does not affect pulmonary artery pressure (Wright and Harrison, 1990) or explant reactivity (JL Wright, unpublished data). This is not surprising, because all models of pulmonary hypertension, including hypoxia, monocrotaline (Partovian et al, 1998), and cigarette smoke (Wright, 1993; Wright and Churg, 1990, 1991; Yamato et al, 1996) take considerable time to develop; for smoke, daily exposure of animals for 4 to 6 months is required before pulmonary hypertension is seen. This relatively long process seems to reflect both slowly developing arterial muscle proliferation and changes in vascular dynamics along with alterations of the pulmonary parenchymal capillary bed (Wright and Churg, 1990; Yamato et al, 1996).

In summary, we have used a microdissection technique to demonstrate that exposure to cigarette smoke induces an up-regulation of genes coding for endothelin, VEGF, and VEGF-R in the mainstem and intraparenchymal pulmonary arteries, a pattern quite distinct from that found in the airways of the same animals. The present study is obviously very acute, and a variety of changes in production of these mediators may occur over the longer term, particularly with chronic smoke exposure. Nonetheless, our data suggest that smoke may well change the vasoconstriction-vasodilation-proliferation/organization balance, a process that may be very important in the vascular remodeling of pulmonary hypertension (Voelkel and Tuder, 1995).

\section{Methods}

\section{Smoke Exposure and Tissue Collection}

Groups of three Sprague-Dawley rats were exposed to the smoke of seven 2R1 research cigarettes (University of Kentucky) using our previously published exposure protocol (Sekhon et al, 1994) or were shamsmoked as controls. At 2 or 24 hours after smoke exposure, we killed the animals by an overdose of urethane anesthesia $(10 \mathrm{mg} / \mathrm{kg})$, immediately removed the trachea and pulmonary artery and placed them into cold $100 \%$ ethanol, and inflated the lungs with cold $100 \%$ ethanol. Tissues were stored at $-80^{\circ} \mathrm{C}$ until analysis. The lung tissue was sectioned coronally and a midcoronal section submitted for paraffin embedding, with direct transfer of the sections into xylene and then into paraffin. Twenty-micron step sections were cut onto diethyl pyrocarbonate-treated (Sigma-Aldrich, Oakville, Ontario) water and collected on cleaned slides.

\section{Microdissection Procedure}

The first slide was stained with HE to act as a scout for identification of airways and vessels. For microdissection the remaining slides were not stained nor was the paraffin removed. Microdissection was performed under an inverted microscope using two 30-gauge needles, first dissecting intrapulmonary arteries, followed by a separate dissection for noncartilaginous intraparenchymal airways. Aggregated microdissected sam- ples from approximately 30 to 50 slides from each animal were combined for mRNA extraction. RNA was extracted directly from the alcohol-fixed main pulmonary artery and trachea. To determine the sizes of intraparenchymal airways or vessels that had been dissected, the greatest transverse diameter of each airway or vessel used for microdissection was measured from the HE-stained sections.

\section{RNA Isolation}

The microdissected tissues were treated with xylene followed by three changes of $100 \%$ ethanol at room temperature and then allowed to air dry. RNA extraction was performed using the PURESCRIPT RNA Isolation Kit (Gentra Systems, Minneapolis, Minnesota) as follows. The PURESCRIPT Cell Lysis Solution was added to the dried tissue, which was then quickly homogenized. The PURESCRIPT Protein-DNA precipitation solution was then added to the tube, which was repeatedly inverted and placed in an ice bath for 5 minutes. The solution was centrifuged at $12000 \times g$ for 6 minutes and the supernatant decanted into a clean tube containing $100 \%$ isopropanol. This tube was again inverted several times and centrifuged at 12000 $\times g$ for 6 minutes. The supernatant was removed, leaving the RNA as a small pellet at the bottom of the tube. The RNA was washed with $70 \%$ ethanol, and another $12000 \times g$ centrifugation was performed. The supernatant was poured off and the pellet allowed to air dry for 10 to 15 minutes. PURESCRIPT RNA Hydration Solution was then added and the tube placed in an ice bath for 30 minutes before proceeding to the reverse transcription step.

\section{RT-PCR Procedure}

RT-PCR was then performed as we have previously described (Wright et al, 1999a). Because fixation and embedding of tissue tends to cut RNA into short lengths, primers were selected to produce target lengths of approximately $200 \mathrm{bp}$. Products were visualized on ethidium bromide-stained gels and quantified using the BioRad Gel Documentation System (BioRad Laboratories, Hercules, California). Expression levels were evaluated by taking the ratio of mRNA for the species of interest to the housekeeping gene.

Malate dehydrogenase (MDH): GenBank accession: AF093773

\#1 (forward): 5' GAGAGTTCATCACGACTGTGC 3' \#2 (reverse): 5' ACGAGTAGAGCAGGTCATCAG 3' Endothelin: GenBank accession: M64711

\#1 (forward): 5' CTCCGAGCCCAAAGTACCATG 3' \#2 (reverse): 5' CAATGTGCTCGGTTGTGTATC 3'

VEGF: GenBank accession: AF062644

\#1 (forward): 5' ATGAGCTTCCTGCAGCATAGCAG $3^{\prime}$

\#2 (reverse): 5' TGCAGGAACATITACACGTCTGC $3^{\prime}$

VEGF-R: GenBank accession: U93306 \#1 (forward): 5' ATGGAGAGCAGGGCGCTGCTAGC $3^{\prime}$ 
\#2 (reverse): 5' TCCTCAGAGTCACGCGGAGTGTT 3' NOS-2: GenBank accession: U26686

\#1 (forward): 5' CCTGGAAGTTTCTCTTCAGAGTCA $3^{\prime}$

\#2 (reverse): 5' GGTCGATGGAGTCACATGCAGCTT 3

NOS-3: GenBank accession: AF093837

\#1 (forward): 5' GATTCTGGCAAGACCGATTACACG $3^{\prime}$

\#2 (reverse): 5' AGGCACAGCACGCGGTGAACCTC $3^{\prime}$

\section{Statistics}

All statistical analyses were performed with the SYSTAT system (Wilkinson, 1988). We compared the data from control animals and smoke-exposed animals at each time period using an analysis of variance, with Bonferroni correction as appropriate.

\section{References}

Betsuyaku T, Griffin GL, Watson MA, and Senior RM (2001). Laser capture microdissection and real-time reverse transcriptase/polymerase chain reaction of bronchiolar epithelium after bleomycin. Am J Respir Cell Mol Biol 25:278-284.

Burrows B, Kettel LJ, Niden AH, Rabinowitz M, and Diener CF (1972). Patterns of cardiovascular dysfunction in chronic obstructive lung disease. N Engl J Med 286:912-917.

Bussolati B, Dunk C, Grohman M, Kontos CD, Mason J, and Ahmed A (2001). Vascular endothelial growth factor receptor-1 modulates vascular endothelial growth factormediated angiogenesis via nitric oxide. Am J Pathol 159:9931008.

Christou H, Yoshida A, Arthur V, Morita T, and Kourembanas $S$ (1998). Increased vascular endothelial growth factor production in the lungs of rats with hypoxia-induced pulmonary hypertension. Am J Respir Cell Mol Biol 18:768-776.

Dadmanesh F and Wright JL (1997). Endothelin-A receptor antagonist $\mathrm{BQ}-610$ blocks cigarette smoke-induced mitogenesis in rat airways and vessels. Am J Physiol 272:L614L618.

Davie N, Haleen SJ, Upton PD, Polak JM, Yacoub MH, and Morrell NW (2002). $\mathrm{ET}_{\mathrm{A}}$ and $\mathrm{ET}_{\mathrm{B}}$ receptors modulate the proliferation of human pulmonary artery smooth muscle cells. Am J Respir Crit Care Med 165:398-405.

Dinh-Xuan AT, Higenbottam TW, Clelland CA, Pepke-Zaba J, Cremona G, Butt AY, Large SR, Wells FC, and Wallwork J (1991). Impairment of endothelium-dependent pulmonaryartery relaxation in chronic obstructive lung disease. $\mathrm{N}$ Engl J Med 324:1539-1547.

Dinh-Xuan AT, Pepke-Zaba J, Butt AY, Cremona G, and Higenbottam TW (1993). Impairment of pulmonary-artery endothelium-dependent relaxation in chronic obstructive lung disease is not due to dysfunction of endothelial cell membrane receptors nor to L-arginine deficiency. Br J Pharmacol 109:587-591.

Goerre S, Staehli C, Shaw S, and Luscher TF (1995). Effect of cigarette smoking and nicotine on plasma endothelin-1 levels. J Cardiovasc Pharm 26:S236-S238.
Goligorsky MS, Tsukahara $H$, Magazine $H$, Andersen $\Pi$, Malik AB, and Bahou WF (1994). Termination of endothelin signaling: Role of nitric oxide. J Cell Physiol 158:485-494.

Hirose S, Hosada Y, Furuya S, Otsuki T, and Ikeda E (2000). Expression of vascular endothelial growth factor and its receptors correlates closely with formation of the plexiform lesion in human pulmonary hypertension. Pathol Int 50:472479 .

Hunley TE, Iwasaki S, Homma T, and Kon V (1995). Nitric oxide and endothelin in pathophysiological settings. Pediatr Nephrol 9:236-244.

Kim H, Yung GL, Marsh JJ, Konopka RG, Pedersen CA, Chiles PG, Morris TA, and Channick RN (2000). Pulmonary vascular remodeling distal to pulmonary artery ligation is accompanied by upregulation of endothelin receptors and nitric oxide synthase. Exp Lung Res 26:287-301.

Kim H, Yung GL, Morris TA, Marsh JJ, Chiles PG, Pedersen CA, Konopka RG, and Channick RN (1999). Endothelin antagonism inhibits pulmonary vascular remodeling in canine chronic pulmonary embolism. Am J Respir Crit Care Med 159:A566.

Kiowski W, Linder L, Stoschitzky K, Pfisterer M, Burckhardt D, Burkart F, and Buhler FR (1994). Diminished vascular response to inhibition of endothelium-derived nitric oxide and enhanced vasoconstriction to exogenously administered endothelin-1 in clinically healthy smokers. Circulation 90:2734.

Klekamp JG, Jarzecka K, Hoover RL, Summar ML, Redmond N, and Perkett EA (1997). Vascular endothelial growth factor is expressed in ovine pulmonary vascular smooth muscle cells in vitro and regulated by hypoxia and dexamethasone. Pediatr Res 42:744-749.

Levin ER (1995). Mechanisms of disease. N Engl J Med 333:356-363.

Murphy ML and Bone RC (1984). Cor pulmonale in chronic bronchitis and emphysema. New York: Futura.

Partovian C, Adnot S, Eddahibi S, Teiger E, Levame M, Dreyfus P, Raffestin B, and Frelin C (1998). Heart and lung VEGF mRNA expression in rats with monocrotaline- or hypoxia-induced pulmonary hypertension. Am J Physiol 275: H1948-H1956.

Redmond EM, Cahill PA, Hodges R, Zhang S, and Sitzmann JV (1996). Regulation of endothelin receptors by nitric oxide in cultured rat vascular smooth muscle cells. J Cell Physiol 166:469-479.

Roland M, Bhowmik A, Sapsford RJ, Seemungal TAR, Jeffries DJ, Warner TD, and Wedzicha JA (2001). Sputum and plasma endothelin-1 levels in exacerbations of chronic obstructive pulmonary disease. Thorax 56:30-35.

Roux S, Breu V, Ertel SI, and Clozel M (1999). Endothelin antagonism with bosentan: A review of potential applications. J Mol Med 77:364-376.

Scalia R, Booth G, and Lefer DJ (1999). Vascular endothelial growth factor attenuates leukocyte-endothelium interaction during acute endothelial dysfunction: Essential role of endothelium-derived nitric oxide. FASEB J 13:1039-1046.

Schulz R, Hummel C, Heinemann S, Seeger W, and Grimminger $F$ (2002). Serum levels of vascular endothelial growth factor are elevated in patients with obstructive sleep apnea and severe nighttime hypoxia. Am J Respir Crit Care Med 165:67-70. 
Sekhon HS, Wright JL, and Churg A (1994). Cigarette smoke causes rapid cell proliferation in small airways and associated pulmonary arteries. Am J Physiol 267:L557-L563.

Trakada G, Marangos M, and Spiropoulos K (2001). Mechanisms of endothelin-1 elevation in chronic obstructive pulmonary disease patients with nocturnal oxyhemoglobin desaturation. Resp 68:134-139.

Tuder RM, Flook BE, and Voelkel NF (1995). Increased gene expression for VEGF and VEGF receptors KDR/KIk and Flt in lungs exposed to acute or to chronic hypoxia. J Clin Invest 95:1798-1807.

Voelkel NF and Tuder RM (1995). Cellular and molecular mechanisms in the pathogenesis of severe pulmonary hypertension. Eur Respir J 8:2129-2138.

Wilkinson L (1988). SYSTAT: The system for statistics. Evanston, Illinois: SYSTAT Inc.

Wort SJ, Woods M, Warner TD, Evans TW, and Mitchell JA (2001). Endogenously released endothelin-1 from human pulmonary artery smooth muscle promotes cellular proliferation. Am J Respir Cell Mol Biol 25:104-110.

Wright JL (1993). The relationship of increased pulmonary artery pressure and airflow obstruction to emphysema. J Appl Physiol 74:1320-1324.

Wright JL and Churg A (1990). Cigarette smoke causes physiologic and morphologic changes of emphysema in the guinea pig. Am Rev Respir Dis 142:1422-1428.

Wright JL and Churg A (1991). Effect of long-term cigarette smoke exposure on pulmonary vascular structure and function in the guinea pig. Exp Lung Res 17:997-1009.
Wright JL, Dai J, Zay K, Price K, Gilks B, and Churg A (1999a). Effects of cigarette smoke on nitric oxide synthase expression in the rat lung. Lab Invest 79:975-983.

Wright JL and Harrison N (1990). Cardiopulmonary effects of a brief exposure to cigarette smoke in the guinea pig. Respiration 57:70-76.

Wright JL and Sun J-P (1999). Dissociation of chronic vascular cell proliferation and vascular contractility after chronic cigarette smoke exposure. Eur Respir J 14:832-838.

Wright JL, Sun J-P, and Churg A (1999b). Cigarette smoke exposure causes constriction of rat lung explant airways. Eur Respir J 14:1095-1099.

Xue C and Johns RA (1996). Upregulation of nitric oxide synthase correlates temporally with onset of pulmonary vascular remodeling in the hypoxic rat. Circulation 28:743-753.

Yamato H, Sun J-P, Churg A, and Wright JL (1996). Cigarette smoke-induced emphysema in guinea pigs is associated with diffusely decreased capillary density and capillary narrowing. Lab Invest 75:211-219.

Yildiz L, Akcay F, Kaynar H, and Bakan N (1996). Increased plasma endothelin-1 in heavy and light smokers. Clin Chem 42:483-484.

Zellers TM, McCormick J, and Wu Y (1994). Interaction among ET-1, endothelium-derived nitric oxide, and prostacyclin in pulmonary arteries and veins. Am J Physiol 267: $\mathrm{H} 139-\mathrm{H} 147$. 